University of South Florida

DIGITAL COMMONS

Digital Commons @ University of

@ UNIVERSITY OF SOUTH FLORIDA

South Florida

6-1993

\title{
Seasonal Variations in Equatorial Atlantic Ocean Zonal Volume Transport at $28^{\circ} \mathrm{W}$
}

\author{
T. Y. Tang \\ University of South Florida \\ Robert $\mathrm{H}$. Weisberg \\ University of South Florida, weisberg@marine.usf.edu
}

Follow this and additional works at: https://digitalcommons.usf.edu/msc_facpub

\section{Scholar Commons Citation}

Tang, T. Y. and Weisberg, Robert H., "Seasonal Variations in Equatorial Atlantic Ocean Zonal Volume Transport at 28"W" (1993). Marine Science Faculty Publications. 390.

https://digitalcommons.usf.edu/msc_facpub/390

This Article is brought to you for free and open access by the College of Marine Science at Digital Commons @ University of South Florida. It has been accepted for inclusion in Marine Science Faculty Publications by an authorized administrator of Digital Commons @ University of South Florida. For more information, please contact digitalcommons@usf.edu. 


\title{
Seasonal Variations in Equatorial Atlantic Ocean Zonal Volume Transport at $28^{\circ} \mathrm{W}$
}

\author{
T. Y. TANG ${ }^{1}$ AND ROBERT H. WEISBERG
}

\author{
Department of Marine Science, University of South Florida, St. Petersburg
}

\begin{abstract}
Zonal volume transport is examined over the upper $150 \mathrm{~m}$ of the water column at $28^{\circ} \mathrm{W}$, using the Seasonal Response of the Equatorial Atlantic experiment moored current meter data at $0.75^{\circ} \mathrm{S}, 0.0^{\circ}$, and $0.75^{\circ} \mathrm{N}$ and a time domain empirical orthogonal function (EOF) analysis to improve spatial and temporal resolution. Gaussian distributions are fit to the mean volume transports per unit width and the fluctuations about these means that are found to be represented by a single EOF mode. The mean volume transport is distributed symmetrically both about the equator and about $75 \mathrm{~m}$ depth, with a meridional scale width of $101 \mathrm{~km}$ and a magnitude of $20.3 \mathrm{~Sv}$. The standard deviation for the fluctuations is $4.7 \mathrm{~Sv}$, and in contrast to the mean the fluctuations are confined to above $100 \mathrm{~m}$ depth, with a larger meridional scale width. The scale width for the mean is consistent with an inertial scale associated with conservation of potential vorticity, while the scale width for the fluctuations is consistent with an equatorial Rossby radius of deformation associated with equatorially trapped waves. These findings support a hypothesis that different physical processes are controlling the volume transport, as integrated from the surface across the Equatorial Undercurrent, over different time scales. On the time scale of the record length average, inertial dynamics appear to be controlling, while on the time scales of the seasonal fluctuations, linear equatorial long-wave dynamics appear to be controlling. However, given the limited record length, there are insufficient degrees of freedom to test this hypothesis statistically.
\end{abstract}

\section{INTRODUCTION}

The development of a quantitative description for the large-scale ocean circulation began in the tropics with Sverdrup's [1947] explanation of the North Equatorial Countercurrent (NECC), a remarkable basin-wide surface current that flows in opposition to the wind stress and owes its existence to the meridional gradient in the vertical component of planetary vorticity. Unbeknownst to ocean theorists at that time was a similarly remarkable "countercurrent" located directly on the equator beneath the surface: the Equatorial Undercurrent (EUC). Also a basin-wide feature, the EUC is a thin veneer of eastward flow embedded within the equatorial thermocline under an intermittent and less well defined surface wind driven South Equatorial Current (SEC). As with the NECC, the EUC owes its existence to the Coriolis parameter's gradient, but with the added complexities of all of those processes, both local and far-field, that determine the structure of the equatorial thermocline and hence the near-surface pressure field that drives the EUC in opposition to the wind stress. The dynamics of these processes, while all related to the Coriolis parameter's gradient, differ in subtle ways. For the mean flow the advection of planetary vorticity results in an intrinsically nonlinear momentum balance [Fofonoff and Montgomery, 1955; Cane, 1980], while for the fluctuations the momentum balance may be described by linear, equatorially trapped planetary waves [Matsuno, 1966; Moore and Philander, 1977]. With this multiplicity of processes it is not surprising that an understanding of the EUC remains incomplete. Not explained, for example, are the magnitudes of the EUC

\footnotetext{
${ }^{1}$ Now at Institute of Oceanography, National Taiwan University, Taipei, Taiwan.
}

Copyright 1993 by the American Geophysical Union.

Paper number 93JC00196.

0148-0227/93/93JC-00196\$05.00 speed and transport, their annual and interannual variabilities, and their differences both between and within the Atlantic and Pacific ocean basins [Halpern and Weisberg, 1989]. The present paper adds to the description of the EUC structure and its volume transport variability over an annual cycle, using observations made during the Seasonal Response of the Equatorial Atlantic (SEQUAL) experiment. The primary finding is that the EUC structure appears to differ for the mean and for the fluctuations. Although one annual cycle is insufficient for statistical hypothesis testing, the data suggest that the mean flow scales according to inertial theory while the fluctuations about the mean scale according to equatorial wave theory.

\section{BACKGROUND}

Katz et al. [1981] provide a review of Atlantic Ocean EUC measurements inclusive of the 1979 Global Weather Experiment. The EUC in the central Atlantic is described as an ever-present eastward flow about $200 \mathrm{~km}$ wide, centered within $100 \mathrm{~km}$ of the equator, with maximum velocity located in the upper part of the thermocline between depths of $50 \mathrm{~m}$ and $125 \mathrm{~m}$. Long-term continuous measurements $(2.7$ years) for the equatorial Atlantic provided by the SEQUAL experiment at $28^{\circ} \mathrm{W}$ [Weisberg et al., 1987] support this description. Eastward flow permeated the upper $200-\mathrm{m}$ measurement domain (except for intermittent westward flow extending down to $50 \mathrm{~m}$ ), with maximum eastward speed generally tracking the upper portion of the thermocline between depths of $50 \mathrm{~m}$ and $100 \mathrm{~m}$. The maximum speed observed at the EUC core had a mean value of $86 \mathrm{~cm} \mathrm{~s}^{-1}$ and an rms deviation of $13 \mathrm{~cm} \mathrm{~s}^{-1}$, and no distinctive annual cycle was observed directly on the equator, either in the maximum speed or in the volume transport per unit width. Katz et al. [1981], using 22 shipboard velocity profile sections spanning the EUC between longitudes of $25^{\circ} \mathrm{W}$ and $33^{\circ} \mathrm{W}$, developed a time series of EUC volume transport by 
TABLE 1. Summary of Equatorial Undercurrent Volume Transport Estimates From the Central Atlantic

\begin{tabular}{|c|c|c|c|}
\hline Longitude & Time & Vertical Range & $\begin{array}{c}\text { Volume } \\
\text { Transport, Sv }\end{array}$ \\
\hline \multicolumn{4}{|c|}{ Philander [1973] } \\
\hline & before 1973 & & $10-37$ \\
\hline \multicolumn{4}{|c|}{ Duing and Hallock [1979] } \\
\hline $28^{\circ} \mathrm{W}$ & July 27 to Aug. $16,1974^{*}$ & $20 \mathrm{~cm} \mathrm{~s}^{-1}$ isotach & $2.9-11.2$ \\
\hline \multicolumn{4}{|c|}{ Bubnov and Egorikhin [1979] } \\
\hline $23.5^{\circ} \mathrm{W}$ & June 27 to July 16,1974 & $0-200 \mathrm{~m}$ & 20.0 \\
\hline $23.5^{\circ} \mathrm{W}$ & July 28 to Aug. 14,1974 & 0-200 m & 15.0 \\
\hline $23.5^{\circ} \mathrm{W}$ & Sept. 1-18, 1974 & $0-200 \mathrm{~m}$ & 19.6 \\
\hline $23.5^{\circ} \mathrm{W}$ & June 27 to Sept. 18,1974 & $0-700 \mathrm{~m}$ & 36.4 \\
\hline \multicolumn{4}{|c|}{ Katz et al. [1979] } \\
\hline $33^{\circ} \mathrm{W}$ & June-July 1974 & $20 \mathrm{~cm} \mathrm{~s}^{-1}$ isotach & 8.9 \\
\hline $28^{\circ} \mathrm{W}$ & June-July 1974 & $20 \mathrm{~cm} \mathrm{~s}^{-1}$ isotach & 9.4 \\
\hline $22^{\circ} \mathrm{W}$ & June-July 1974 & $20 \mathrm{~cm} \mathrm{~s}^{-1}$ isotach & 11.9 \\
\hline $16^{\circ} \mathrm{W}$ & June-July 1974 & $20 \mathrm{~cm} \mathrm{~s}^{-1}$ isotach & 12.3 \\
\hline $10^{\circ} \mathrm{W}$ & June-July 1974 & $20 \mathrm{~cm} \mathrm{~s}^{-1}$ isotach & 7.3 \\
\hline \multicolumn{4}{|c|}{ Katz et al. [1981] } \\
\hline western Atlantic & composite, 1979 & $20 \mathrm{~cm} \mathrm{~s}^{-1}$ isotach & 21.0 \\
\hline western Atlantic & composite, 1979 & $20 \mathrm{~cm} \mathrm{~s}^{-1}$ isotach & $10-44$ \\
\hline \multicolumn{4}{|c|}{ Hisard and Henin [1984] } \\
\hline $23^{\circ} \mathrm{W}$ & April 1983 & $20 \mathrm{~cm} \mathrm{~s}^{-1}$ isotach & 9.0 \\
\hline $35^{\circ} \mathbf{W}$ & April 1983 & $20 \mathrm{~cm} \mathrm{~s}^{-1}$ isotach & 11.2 \\
\hline $4^{\circ} \mathrm{W}$ & summer 1983 & $20 \mathrm{~cm} \mathrm{~s}^{-1}$ isotach & 4.1 \\
\hline $10^{\circ} \mathrm{W}$ & summer 1983 & $20 \mathrm{~cm} \mathrm{~s}^{-1}$ isotach & 3.5 \\
\hline $23^{\circ} \mathrm{W}$ & summer 1983 & $20 \mathrm{~cm} \mathrm{~s}^{-1}$ isotach & 5.6 \\
\hline $35^{\circ} \mathrm{W}$ & summer 1983 & $20 \mathrm{~cm} \mathrm{~s}^{-1}$ isotach & 8.8 \\
\hline \multicolumn{4}{|c|}{ Hisard and Henin [1987] } \\
\hline $23^{\circ} \mathrm{W}$ & Oct. 1982 & $20 \mathrm{~cm} \mathrm{~s}^{-1}$ isotach & 26.0 \\
\hline $23^{\circ} \mathrm{W}$ & April 1983 & $20 \mathrm{~cm} \mathrm{~s}^{-1}$ isotach & 14.0 \\
\hline $23^{\circ} \mathrm{W}$ & July 1983 & $20 \mathrm{~cm} \mathrm{~s}^{-1}$ isotach & 6.0 \\
\hline $23^{\circ} \mathrm{W}$ & Oct. 1983 & $20 \mathrm{~cm} \mathrm{~s}^{-1}$ isotach & 25.0 \\
\hline $23^{\circ} \mathrm{W}$ & Jan. 1984 & $20 \mathrm{~cm} \mathrm{~s}^{-1}$ isotach & 11.0 \\
\hline $23^{\circ} \mathrm{W}$ & April 1984 & $20 \mathrm{~cm} \mathrm{~s}^{-1}$ isotach & 11.0 \\
\hline $23^{\circ} \mathrm{W}$ & July 1984 & $20 \mathrm{~cm} \mathrm{~s}^{-1}$ isotach & 12.0 \\
\hline
\end{tabular}

*For 11 sections.

integrating, over the meridional plane, eastward speed in excess of $20 \mathrm{~cm} \mathrm{~s}^{-1}$. This time series had a mean value of $20.7 \mathrm{~Sv}$ and a standard deviation of $6.9 \mathrm{~Sv}$, and it showed maximum (minimum) volume transport in boreal spring (summer) coincident with weak (strong) easterly wind stress. Using the numerical model results of Cane [1979], Katz et al. framed their findings in terms of the response times for the development of the basin-wide pressure gradient. Peak transport in boreal spring was attributed to an eastward acceleration of the near-surface currents in response to an unbalanced pressure gradient following the cessation of the easterlies, and minimum transport was attributed to a delayed response as the pressure gradient adjusted by equatorial wave propagation.

Hisard and Henin [1987] provide an additional review of Atlantic Ocean EUC volume transport determinations inclusive of the Programme Français Océan et Climat dans l'Atlantique Equatorial (FOCAL), the French-led companion program to SEQUAL. Volume transports for eastward speed in excess of $20 \mathrm{~cm} \mathrm{~s}^{-1}$ were estimated from eight shipboard velocity profiling sections obtained along $23^{\circ} \mathrm{W}$ during 1983-1984. A clear annual cycle was not evident, although minimum transport was observed in boreal summer 1983.
A summary of many of the volume transport estimations that have been made for the Atlantic Ocean EUC is given in Table 1. Philander's [1973] review of observations prior to that date gave a range of 10-37 Sv. From the Global Atlantic Tropical Experiment (GATE) data at $23.5^{\circ} \mathrm{W}$, Bubnov and Egorikhin [1979] estimated the transport above $200 \mathrm{~m}$ to be 15-20 Sv, with rapid temporal variations occurring over time scales shorter than a month. Similar variations in time and in longitude along the equator during GATE were reported by Duing and Hallock [1979] and Katz et al. [1979]. From these findings it is clear that individual sections may be biased by nonsynoptic sampling or aliased by high-frequency variability. While the measurement techniques and methods of integration have varied, the Katz et al. [1981] results, and their composite time series, pieced together using dynamical arguments, appear to be representative of the seasonal variations, and it is to this description that the present paper adds by analyzing current meter data obtained from the SEQUAL surface moorings.

\section{Data Description}

The SEQUAL and FOCAL moored current meter array (for the period considered herein) may be broken into a zonal 
array, with moorings along the equator at $28^{\circ} \mathrm{W}, 24^{\circ} \mathrm{W}$, $15^{\circ} \mathrm{W}$, and $4^{\circ} \mathrm{W}$, and a meridional array, with moorings along $28^{\circ} \mathrm{W}$ at $0.75^{\circ} \mathrm{S}, 0.0^{\circ}$, and $0.75^{\circ} \mathrm{N}$. For the present purposes the zonal array data are used to show the monthly-mean evolution of the thermocline and of the zonal flow along the equator, and the meridional array data are used to estimate the equatorial zonal volume transport at $28^{\circ} \mathrm{W}$.

Monthly-mean isotherm and isotach contours, drawn over the upper $150 \mathrm{~m}$ in the equatorial zonal plane, are shown in Figure 1 for the period March 1983 through September 1984. During this time the zonal component of surface wind stress, the principal determinant of low-frequency equatorial circulation variability, underwent a large annual cycle, with strong easterlies commencing in boreal spring and then relaxing in boreal winter [Garzoli and Katz, 1984; Colin and Garzoli, 1987]. The evolutions of the equatorial thermocline and the zonal pressure gradient in response to these wind stress changes are shown, for example, by Hisard and Henin [1987], Katz [1987], and Weisberg and Tang [1987]. Figure 1 shows that the thermocline first upwells and begins to increase its tilt in May and June 1983, after the easterlies intensify, reaching its steepest slope in July 1983. The thermocline then downwells and reduces its tilt from July through September 1983, as the basin-wide adjustment continues. Very little change is observed from October through December 1983, when the thermocline appears to be in relative equilibrium with the winds. As the easterlies relax from December 1983 to January 1984, the thermocline slope also relaxes, with the slope even reversing sign in the western part of the basin in April 1984. The cycle repeats in boreal spring 1984 after the easterlies again intensify. An explanation for the observed thermocline and the attendant zonal pressure gradient variability is given by Weisberg and Tang [1987, 1990] in terms of equatorial long waves forced by the zonal wind stress changes.

The zonal currents (also shown in Figure 1) when viewed along the equator show that the EUC core tends to track the thermocline. The EUC is well developed throughout the measurement period despite the unusually large easterly relaxation event of boreal winter 1984 . The largest variability appears to occur in the near-surface flow. The westward flowing SEC is weak during March and April 1983. It then accelerates to maximum values in July 1983 after the easterlies intensify. It is also convergent at this time, while the thermocline is downwelling. The SEC then decelerates to weaker values in August and September 1983 before accelerating again to larger values in November and December 1983. These behaviors are also related to the basin-wide adjustment of the zonal pressure gradient [e.g., Philander and Pacanowski, 1986; Weisberg and Tang, 1987]. Since zonal transport variability arises from an imbalance between the vertically integrated zonal pressure gradient and the surface wind stress, these monthly-mean data suggest that the transport variability is controlled more by the variations in the near-surface flow than in the strength of the subsurface EUC.

\section{Zonal Volume Transport at $28^{\circ} \mathrm{W}$}

The zonal volume transport associated with the surface SEC and subsurface EUC is examined using the current meter measurements made between depths of $10 \mathrm{~m}$ and 150 $\mathrm{m}$ along $28^{\circ} \mathrm{W}$ at $0.75^{\circ} \mathrm{N}, 0.0^{\circ}$, and $0.75^{\circ} \mathrm{S}$. The locations and record lengths for these measurements (made with the EG\&G Sea Links Systems, Inc., vector-averaging current meters) are listed in Table 2 . All the records were truncated to a common start time of 0000 UT on March 4, 1983, and the record lengths vary from 5764 to 9188 hours. The zonal volume transport integrated over the meridional plane, TR, is calculated from

$$
\mathrm{TR}=\iint u(y, z) d y d z
$$

where $u(y, z)$ is the zonal component of velocity. The integral is evaluated using two methods. Common to both methods is a trapezoidal integration in the vertical at each location. The meridional integration is then performed either by summing the vertical integral at each location times $\mathbf{8 2 . 5}$ $\mathrm{km}\left(0.75^{\circ}\right.$ of latitude) or by fitting a Gaussian function using the method of linear least squares and then integrating the Gaussian function, i.e.,

$$
T(y)=A_{o} \exp \left[-\left(y-y_{o}\right) /\left(2^{1 / 2} \sigma\right)^{2}\right]
$$

whence

$$
\mathrm{TR}=\int T(y) d y,
$$

where $A_{o}, y_{o}$, and $\sigma$ are the amplitude, centroid, and standard deviation of the Gaussian function, respectively. Both methods are somewhat arbitrary, the first based upon the array dimensions and the second based upon a Gaussian fit. The Gaussian fit, having been used by previous authors [e.g., Katz et al., 1981], provides a measure for comparison with previous studies.

Given the variations in record length, the data set was formed into two parts. Data set A contains all 13 time series, truncated to match the shortest record length of 5764 hours. Data set B contains the nine longest time series, having record lengths of 9188 hours. The differences between the record length mean values for the east components of velocity from these two data sets are small, as given in Table 3 , and the spatial distribution of the data set $\mathrm{A}$ mean values is shown in Figure 2. Symmetry is observed about the EUC core, located between $75 \mathrm{~m}$ and $100 \mathrm{~m}$ depths, wherein eastward speeds exceed $80 \mathrm{~cm} \mathrm{~s}^{-1}$. The mean flow is eastward everywhere except near the surface at the northernmost location; that is, on average the SEC was not well developed near $0^{\circ}, 28^{\circ} \mathrm{W}$ during 1983 . Integrating the zonal flow using method 1 or method 2 results in mean volume transport estimates of 15 or $21 \mathrm{~Sv}$, respectively. The method 2 result is larger owing to the less arbitrary cutoff in meridional scale. The Gaussian distribution for the volume transport per unit width associated with this estimate is shown in Figure 3. The parameters of this Gaussian fit, $A_{o}$, $y_{o}$, and $\sigma$, are $80 \mathrm{~cm} \mathrm{~s}^{-1},-14.5 \mathrm{~km}\left(0.13^{\circ} \mathrm{S}\right)$, and $101 \mathrm{~km}$, respectively. The magnitude of the estimated transport is the same as that obtained, on average, in the western equatorial Atlantic by Katz et al. [1981], where integration was performed between eastward flowing $20 \mathrm{~cm} \mathrm{~s}^{-1}$ isotachs. This agreement, on average, with the Katz et al. [1981] findings is more than fortuitous, since their analyses showed that a Gaussian fit to the transports per unit width at the individual stations gave estimates indistinguishable from those ac- 


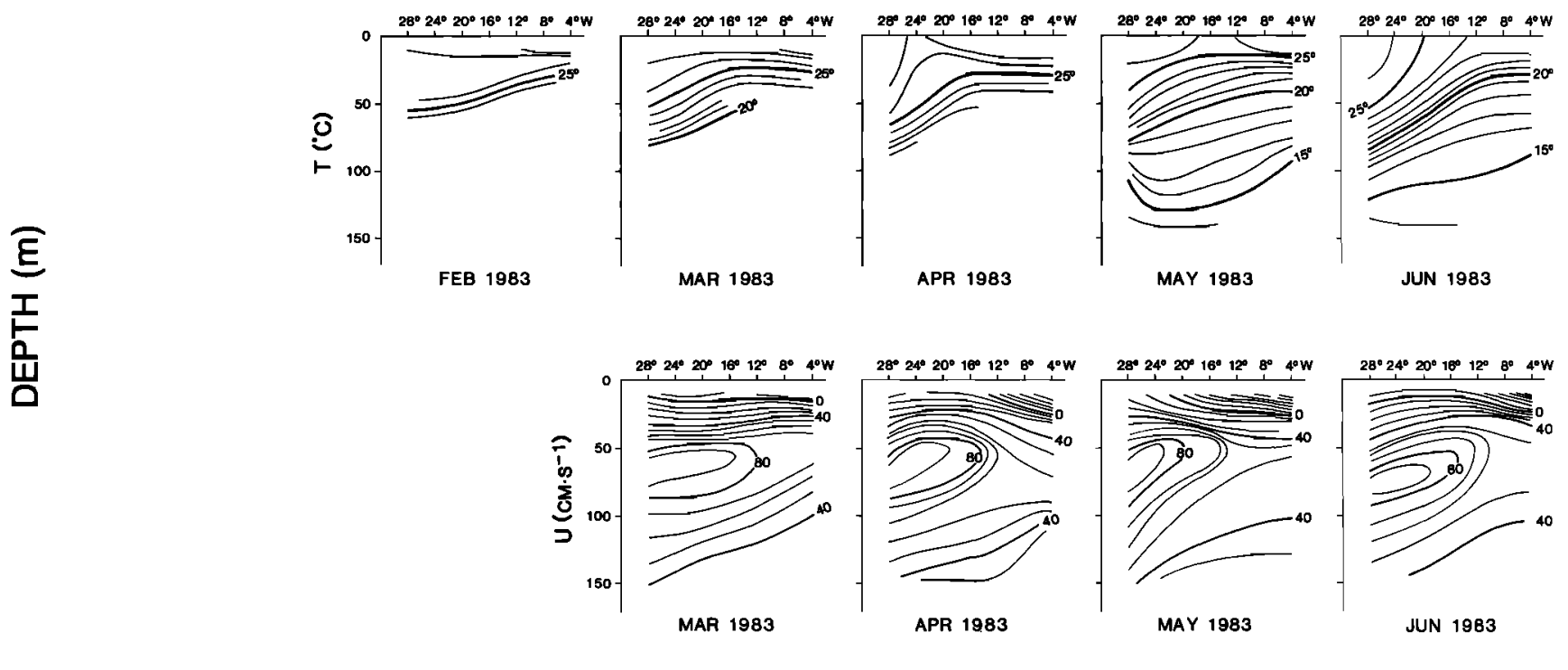

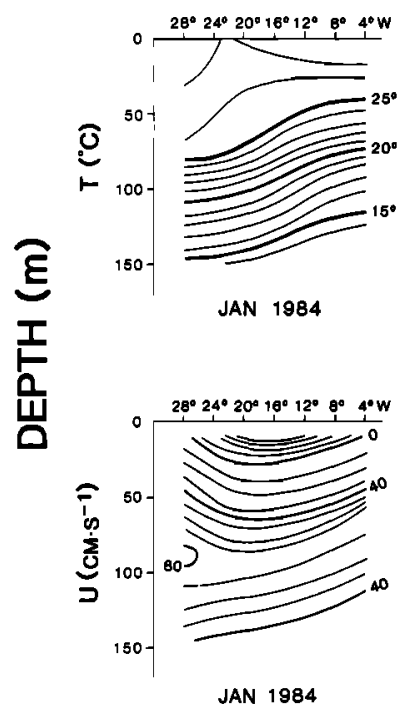

JAN 1984

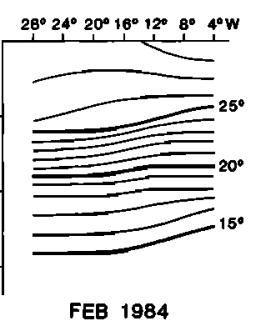

FEB 1984

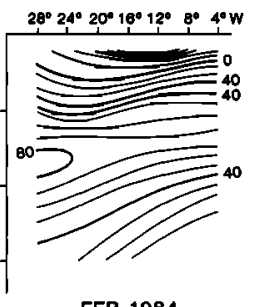

FEB 1984

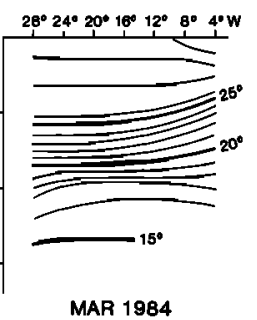

MAR 1984

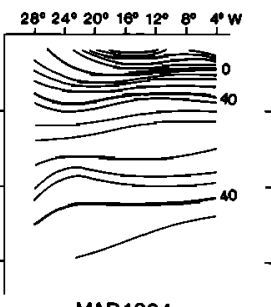

MAR 1984

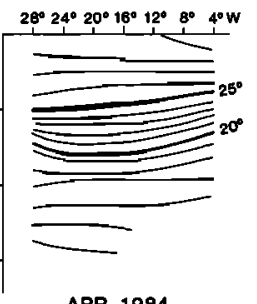

APR 1984

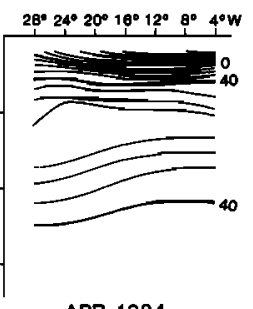

APR 1984

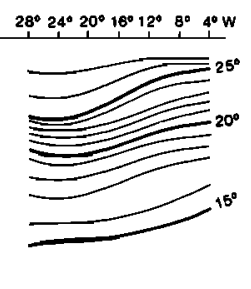

MAY 1984

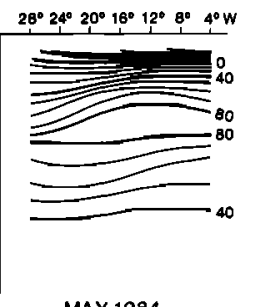

MAY 1984

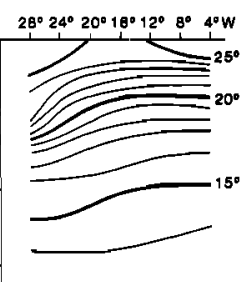

JUN 1984

Fig. 1. Monthly-mean isotherm and zonal component isotach contours drawn in the equatorial zonal plane over the upper $150 \mathrm{~m}$ between $28^{\circ} \mathrm{W}$ and $4^{\circ} \mathrm{W}$. The data are from surface-moored current meters deployed during the SEQUAL and FOCAL programs.

quired by direct numerical integration if the measurements had sufficient meridional extent.

In an attempt to fully utilize the available spatial and temporal sampling of data sets $\mathrm{A}$ and $\mathrm{B}$ a time domain empirical orthogonal function (EOF) analysis [e.g., Wallace and Dickinson, 1972] is used in describing the zonal volume transport fluctuations that occur about the record length mean values. Noting that EOFs decompose the data into spatial patterns and time evolution functions, the objective is to estimate the volume transport variations over a full year by using spatial functions determined from the shorter but spatially more complete data set $\mathrm{A}$ and time evolution functions determined from the longer but spatially less complete data set B. EOFs were thus fit to both data sets as

$$
\begin{aligned}
& D_{\mathrm{A}}(x, t)=\sum e_{\mathrm{A} i}(x) r_{\mathrm{A} i}(t) \\
& D_{\mathrm{B}}(x, t)=\sum e_{\mathrm{B} i}(x) r_{\mathrm{B} i}(t),
\end{aligned}
$$

where the $D(x, t)$ are the data matrices, consisting of de-meaned time series as row vectors, with $x$ and $t$ representing position and time, respectively; $e(x)$ are the spatial eigenfunctions; and $r(t)$ are the time evolution functions, with subscript $i$ representing the mode number. The eigenfunctions are calculated from the covariance matrix of the hourly averaged zonal velocity component time series, and the time evolution functions are calculated by projecting these hourly averaged data onto the eigenfunctions. Hourly averaged data were used so that the time and space correlation of the data determines the smoothing via the EOF analysis. For comparison a parallel analysis was also performed using a 10-day low-pass-filtered version of the data set to insure that the higher-frequency variations are not biasing the spatial and temporal structure of the EOF modes that account for the volume transport fluctuations. Since both the hourly averaged and the 10-day low-pass-filtered 


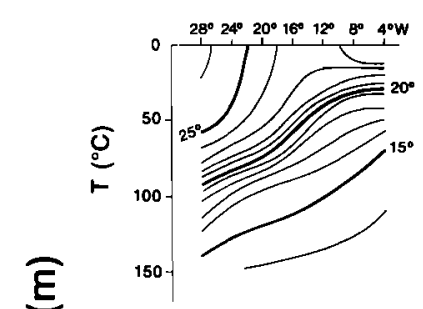

JUL 1983

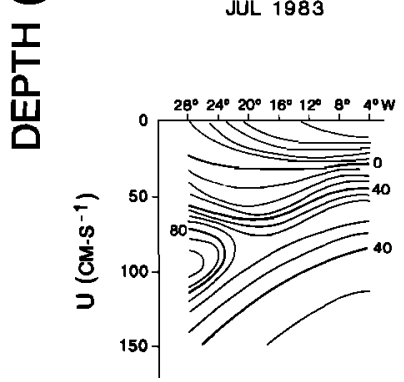

JUL 1983

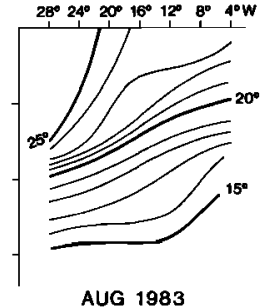

AUG 1983

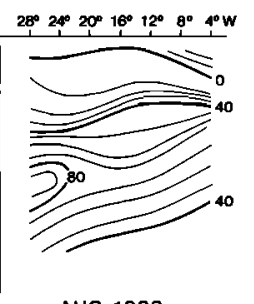

AUG 1983

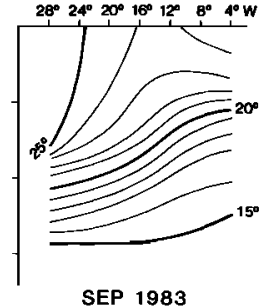

SEP 1983

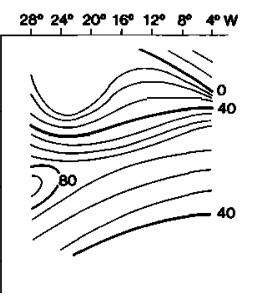

SEP 1983

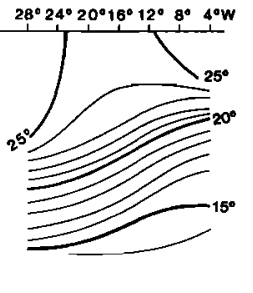

OCT 1983

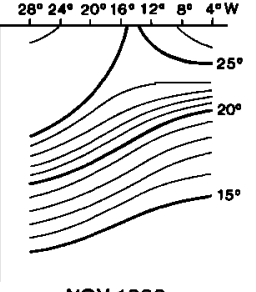

NOV 1983

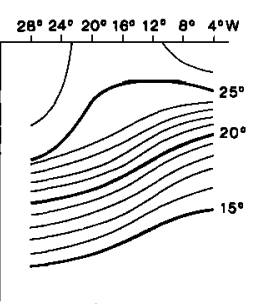

DEC 1983

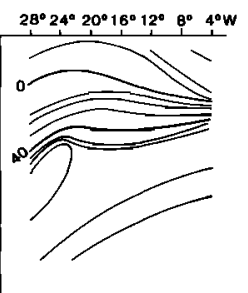

OCT 1983

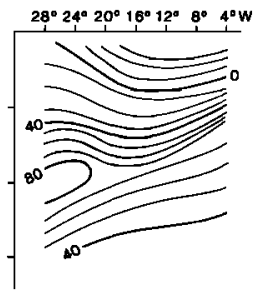

NOV 1983

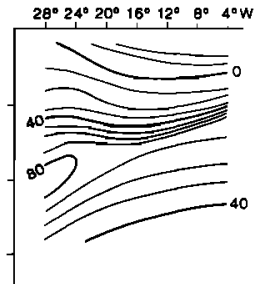

DEC 1983

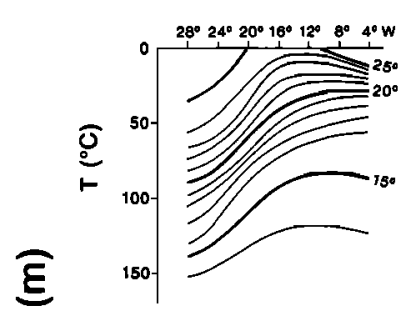

JUL 1984

吉

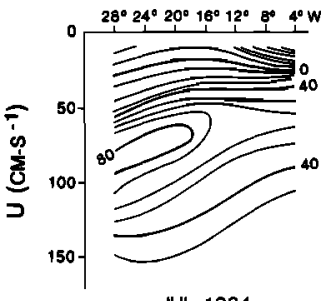

JUL 1984

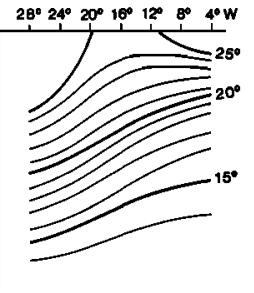

AUG 1984

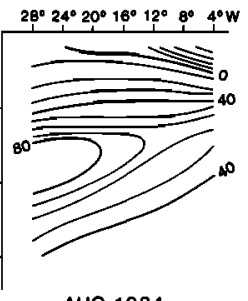

AUG 1984

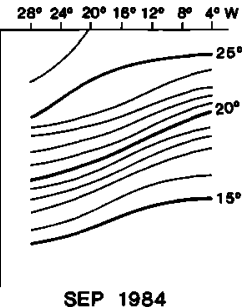

SEP 1984

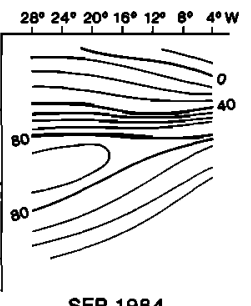

Fig. 1. (continued)

data gave very similar results for the low-frequency volume transport variations, it was decided to retain the higherfrequency fluctuations for completeness.

The variances and the percentages of total variance accounted for by the first five EOF modes of data sets $A$ and $B$ are listed in Table 4. These modes account for 72 and $74 \%$ of the total variances for data sets $A$ and $B$, respectively. While the zonal current field requires several EOF modes to represent itself, the zonal transport does not, since highermode contributions to transport tend to individually cancel upon integration. Figure 4 compares the transport derived from the first EOF mode with that estimated directly from the data, where the shorter but spatially more complete data set $A$, along with method 1 for the meridional integration, is used. The first EOF mode accounts for most of the volume transport variability.

Inspection of the eigenfunctions reveals why the transport variations are accounted for by the first mode. Figure 5 shows the first two eigenfunctions computed from data set A. The first eigenfunction is nearly symmetric about the equator and in phase over the upper $100 \mathrm{~m}$ of the water column, with maximum values around $50 \mathrm{~m}$. This distribution, with most of the variability occurring within and above the thermocline, is quite different from the mean distribution which is symmetric about the EUC core. The second eigenfunction is antisymmetric about both the equator and $75 \mathrm{~m}$ depth, so when integrated over the meridional plane its contribution to the volume transport is very small. The third and fourth eigenfunctions (not shown) contribute slightly more to the total volume transport than the second mode but much less than the first mode, with small but noncancelling values located near the surface and $75 \mathrm{~m}$ depth, respectively. As with the dominant first mode, the volume transport variability for these modes is also confined to the region within and above the thermocline.

To the extent that the EOF modes from data sets A and B are similar, the estimated volume transport time series may be extended by using the spatial eigenfunction from data set $A$ and the time evolution function from data set $B$. Since the transport estimate involves the multiplication of the inte- 
TABLE 2. Locations and Record Lengths for the Time Series Used in the Zonal Volume Transport Time Series Estimation at $28^{\circ} \mathrm{W}$

\begin{tabular}{|c|c|c|c|}
\hline \multirow[b]{2}{*}{ Depth, m } & \multicolumn{2}{|c|}{ Ending Time } & \multirow{2}{*}{$\begin{array}{l}\text { Record Length, } \\
\text { hours }\end{array}$} \\
\hline & Hour, UT & Date & \\
\hline \multicolumn{4}{|c|}{$0^{\circ} 45^{\prime} N, 28^{\circ} 11^{\prime} W$} \\
\hline 10 & 2000 & March 20, 1984 & 9188 \\
\hline 75 & 2000 & March 20, 1984 & 9188 \\
\hline 100 & 0400 & Oct. 30,1983 & 5764 \\
\hline 150 & 2000 & March 20, 1984 & 9188 \\
\hline \multicolumn{4}{|c|}{$0^{\circ} 03^{\prime} N, 28^{\circ} 10^{\prime} W$} \\
\hline 10 & 2000 & March 20, 1984 & 9188 \\
\hline 50 & 2000 & March 20, 1984 & 9188 \\
\hline 75 & 2000 & March 20, 1984 & 9188 \\
\hline 100 & 2000 & March 20, 1984 & 9188 \\
\hline 150 & 0300 & Nov. 3,1983 & 5859 \\
\hline \multicolumn{4}{|c|}{$0^{\circ} 44^{\prime} S, 28^{\circ} 10^{\prime} W$} \\
\hline 10 & 2000 & March 20, 1984 & 9188 \\
\hline 75 & 1600 & Dec. 13,1983 & 6808 \\
\hline 150 & 2000 & March 20, 1984 & 9188 \\
\hline
\end{tabular}

Starting time for all readings is 0000 UT, March 4, 1983.

grated spatial eigenfunction with the time evolution function, it is the spatial correlation and the temporal coherency between these functions that determine the validity of the interchange. The data sets $\mathrm{A}$ and $\mathrm{B}$ first-mode eigenfunctions are very similar, having a spatial correlation coefficient of 0.97 . They are also temporally coherent and in phase with coherence squared greater than 0.9 for time scales longer than 2 days. This similarity only pertains to mode 1 ; modes 2 and 3 were not similar. For this particular data set then, the interchange of spatial and temporal functions for the primary transport mode 1 is justified to the extent that the unresolved longer time scale fluctuations behave similarly to fluctuations on time scales that are resolved. This of course raises the question of statistical significance for the EOF modes to begin with. Given the fact that we are attempting to describe an annual cycle with roughly one year of data (only 8 months for data set $\mathrm{A}$ ), there are not adequate degrees of freedom to establish the statistical significance of the EOF modes [e.g., Overland and Preisendorfer, 1982; North et al., 1982]. A much longer data set would be required to do this.

A volume transport time series is estimated by fitting Gaussian distributions, at each hourly time step, to the sum of the vertically integrated mean values plus the vertically integrated first EOF mode, at each of the three latitudes. The results are shown in Figure 6, including time series for the three parameters of the Gaussian fit: $A_{o}, y_{o}$, and $\sigma$. Along with broadband variability an annual cycle is observed, with maximum values in boreal winter/spring and minimum valúes in boreal summer/fall. The parameters to the Gaussian fit show variability about the values previously given for the mean alone. In terms of volume transport the range is between $9 \mathrm{~Sv}$ and $34 \mathrm{~Sv}$, with a mean value of $20.3 \mathrm{~Sv}$ and a standard deviation of $4.7 \mathrm{~Sv}$. High-frequency variability is substantial, and aliasing by fluctuations with time scales from semidiurnal to several days could result in shipboard profile estimate uncertainty of up to $10 \mathrm{~Sv}$.

By fitting a Gaussian distribution to the fluctuations alone (not shown), as represented by the first EOF mode, the fluctuation scale width is found to be much larger than that for the mean flow. It ranged between $190 \mathrm{~km}$ and $360 \mathrm{~km}$, as
TABLE 3. The Zonal Component of Velocity Mean Values for Data Sets A and B

\begin{tabular}{ccc}
\hline & \multicolumn{2}{c}{ Zonal Velocity Component, cm s } \\
\cline { 2 - 3 } Depth, m & Data Set A & Data Set B \\
\hline & $0^{\circ} 45^{\prime} N, 28^{\circ} 11^{\prime} W$ & \\
10 & -16.23 & -15.88 \\
75 & 44.68 & 46.52 \\
100 & 55.06 & $\cdots$ \\
150 & 31.09 & 28.02 \\
& $0^{\circ} 03^{\prime} N, 28^{\circ} 10^{\prime} W$ & \\
10 & 1.08 & 0.73 \\
50 & 48.51 & 44.25 \\
75 & 80.23 & 75.47 \\
100 & 83.12 & 81.27 \\
150 & 47.16 & $\cdots$ \\
200 & 26.53 & $\cdots$ \\
& $0^{\circ} 44^{\prime} S, 28^{\circ} 10^{\prime} W$ & \\
10 & 0.80 & 0.80 \\
75 & 68.85 & $\cdots$ \\
150 & 35.68 & 34.44 \\
\hline
\end{tabular}

compared with $101 \mathrm{~km}$ found for the mean distribution alone. With only three points for fitting a Gaussian distribution having three parameters the scale width determination is sensitive to the data set. However, the range of values excludes the value found for the mean, and these values are closer to an equatorial Rossby radius of deformation than they are to an inertial length scale. For example, the scale width, using a reduced gravity Kelvin wave speed of $160 \mathrm{~cm}$ $\mathrm{s}^{-1}$, as in the study by Weisberg and Tang [1987], is $264 \mathrm{~km}$.

For the same reason that we cannot establish the statistical significance of the EOF mode calculation (insufficient degrees of freedom), we cannot distinguish statistically between the Gaussian scale widths found for the distribution of the mean transports per unit width (which are also statistically indistinguishable from one another) and the distribution for the fluctuations about the mean. Thus we can

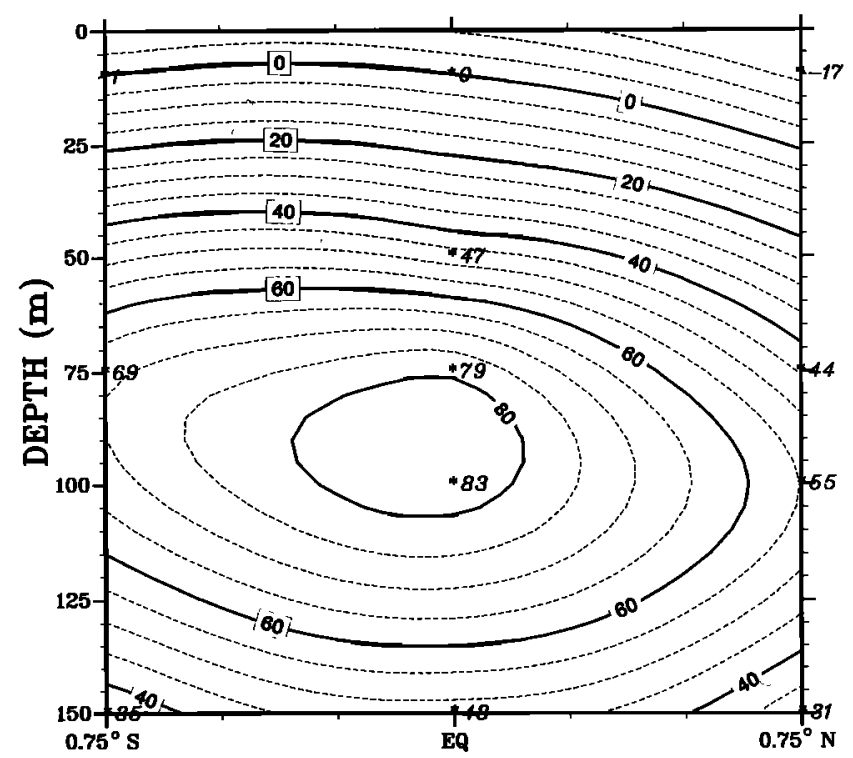

Fig. 2. Isotach contours for the mean zonal component drawn in the meridional plane at $28^{\circ} \mathrm{W}$ over the upper $150 \mathrm{~m}$ between $0.75^{\circ} \mathrm{S}$ and $0.75^{\circ} \mathrm{N}$, for data set $\mathrm{A}$. 


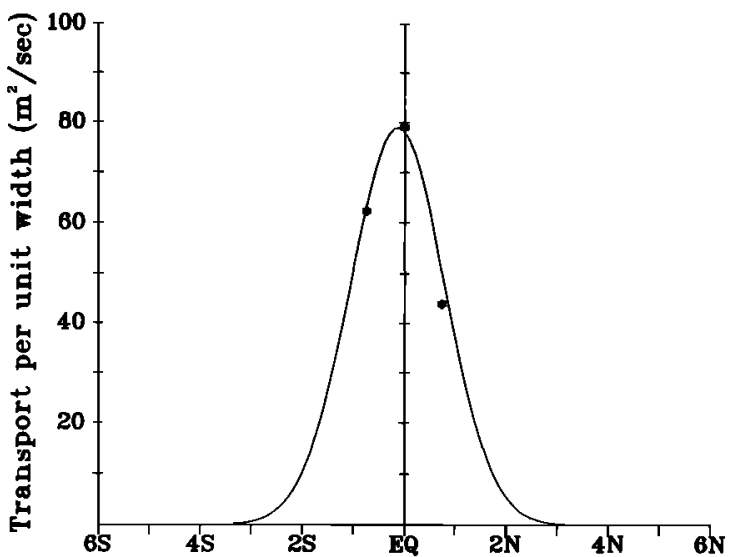

Fig. 3. A linear least squares Gaussian distribution fit to the mean zonal volume transport per unit width for data set $A$.

only form a hypothesis based upon descriptive findings; we cannot test this hypothesis statistically.

\section{Discussion ANd Summary}

The seasonal evolution observed in the zonal volume transport time series may be compared with linear theory. Transport features of particular interest are the peak values found in March 1983, the subsequent decrease to a relative minimum at the end of June 1983, the relative maximum in September 1983, and the maximum values that appear again in boreal winter 1984. These features are all predicted by linear theory, given the temporal evolution of the basin-wide easterly wind stress variability during that time. Weisberg and Tang [1990], using an analytical equatorial long-wave simulation, show that the March 1983 peak arises as a response to a week-long basin-wide westerly wind stress event that occurred at that time. The easterlies intensified after this event, and linear theory then predicts a decrease in eastward transport as the near-surface currents accelerate in response to these winds. This acceleration, which sets up the SEC, continues until an opposing zonal pressure gradient is established via wave reflection from the western boundary. The SEC is short-lived, however, since wave reflection from the eastern boundary causes the eastward directed pressure gradient force to overshoot its intended equilibrium [Weisberg and Weingartner, 1986] with the wind stress, thereby decelerating the westward SEC and even causing this flow to reverse. Further reflections again accelerate the SEC westward, resulting in an apparent semiannual cycle that is most pronounced in the eastern half of the basin. After the easterlies relax in December 1983, the transport increases as the currents are accelerated eastward in response to the existing eastward pressure gradient.

Along with linear theory the near-surface currents are known to be affected by nonlinear processes [e.g., Philander and Pacanowski, 1986]. For example, the reason why the transport does not decrease as rapidly as linear theory would predict after the March 1983 event is the influence of nonlinear waves generated by barotropic instability within the cyclonic shear region of the SEC [Weisberg and Weingartner, 1988]. The velocity time series show a strong eastward acceleration at $28^{\circ} \mathrm{W}$ in May 1983 due to these instability waves at the time when the basin-wide linear
TABLE 4. Variances and Percentages of Variance Accounted for by the First Five EOF Modes Computed for Data Sets $A$ and $B$

\begin{tabular}{cccccc}
\hline & \multicolumn{2}{c}{ Data Set A } & & \multicolumn{2}{c}{ Data Set B } \\
\cline { 2 - 3 } \cline { 5 - 6 } $\begin{array}{c}\text { EOF } \\
\text { Mode }\end{array}$ & $\begin{array}{l}\text { Variance, } \\
\left(\mathrm{cm} \mathrm{s}^{-1}\right)^{2}\end{array}$ & Percentage & & $\begin{array}{l}\text { Variance, } \\
\left(\mathrm{cm} \mathrm{s}^{-1}\right)^{2}\end{array}$ & Percentage \\
\hline 1 & $24.1 \times 10^{3}$ & 40.0 & & $19.7 \times 10^{3}$ & 44.3 \\
2 & $12.0 \times 10^{3}$ & 19.9 & & $8.1 \times 10^{3}$ & 18.2 \\
3 & $7.1 \times 10^{3}$ & 11.8 & & $4.9 \times 10^{3}$ & 11.0 \\
4 & $3.9 \times 10^{3}$ & 6.5 & & $3.8 \times 10^{3}$ & 8.5 \\
5 & $3.0 \times 10^{3}$ & 5.0 & & $2.8 \times 10^{3}$ & 6.3 \\
\hline
\end{tabular}

response by itself would impart a westward acceleration. Spatially unresolved wind stress variations would also cause the observed evolution to depart from any model result.

The zonal volume transport determined from the SEQUAL mooring data also agrees in many respects with the Katz et al. [1981] results. Quantitatively, the means and standard deviations are nearly equal. Both time series show an eastward transport pulse in boreal spring, a minimum in early summer, and a relative maximum in late summer; and while the explanations given there and here are slightly different, a linear response model forms the conceptual basis for both. Also, if one combines the EUC with the SEC transport calculations made from the primitive equation numerical model simulation of Philander and Pacanowski [1986], qualitative agreement is again found. Agreement is not found, however, between the SEQUAL mooring data results and those of the FOCAL shipboard estimates made at $23^{\circ} \mathrm{W}$ during the same year by Hisard and Henin [1987] (see Table 1). This may be due to aliasing and biasing, a question that these authors also raise in their discussion.

Two different meridional length scales are suggested by the results: an inertial length scale $L_{l}$ for the mean zonal volume transport and an equatorial Rossby radius of deformation, $L_{R}$, for the volume transport fluctuations. $L_{I}$ relates the origin of a water parcel displaced meridionally to the equator from some initial latitude with the eastward speed that the parcel attains on the equator by conserving potential vorticity [Fofonoff and Montgomery, 1955; Cane, 1980]. If $u_{0}$ is the eastward speed at the equator owing to a displace-

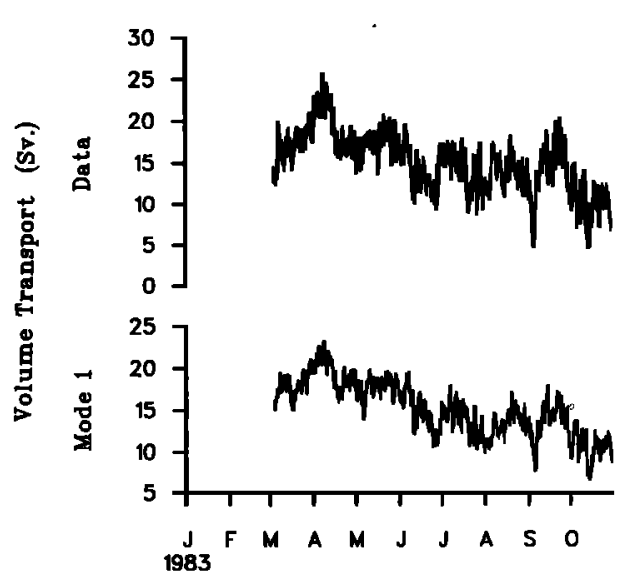

Fig. 4. A comparison between the zonal volume transports over the upper $150 \mathrm{~m}$ at $28^{\circ} \mathrm{W}$ computed (using data set $A$ and method 1 for the meridional integration) (top) directly from the data and (bottom) from the means plus EOF mode 1. 

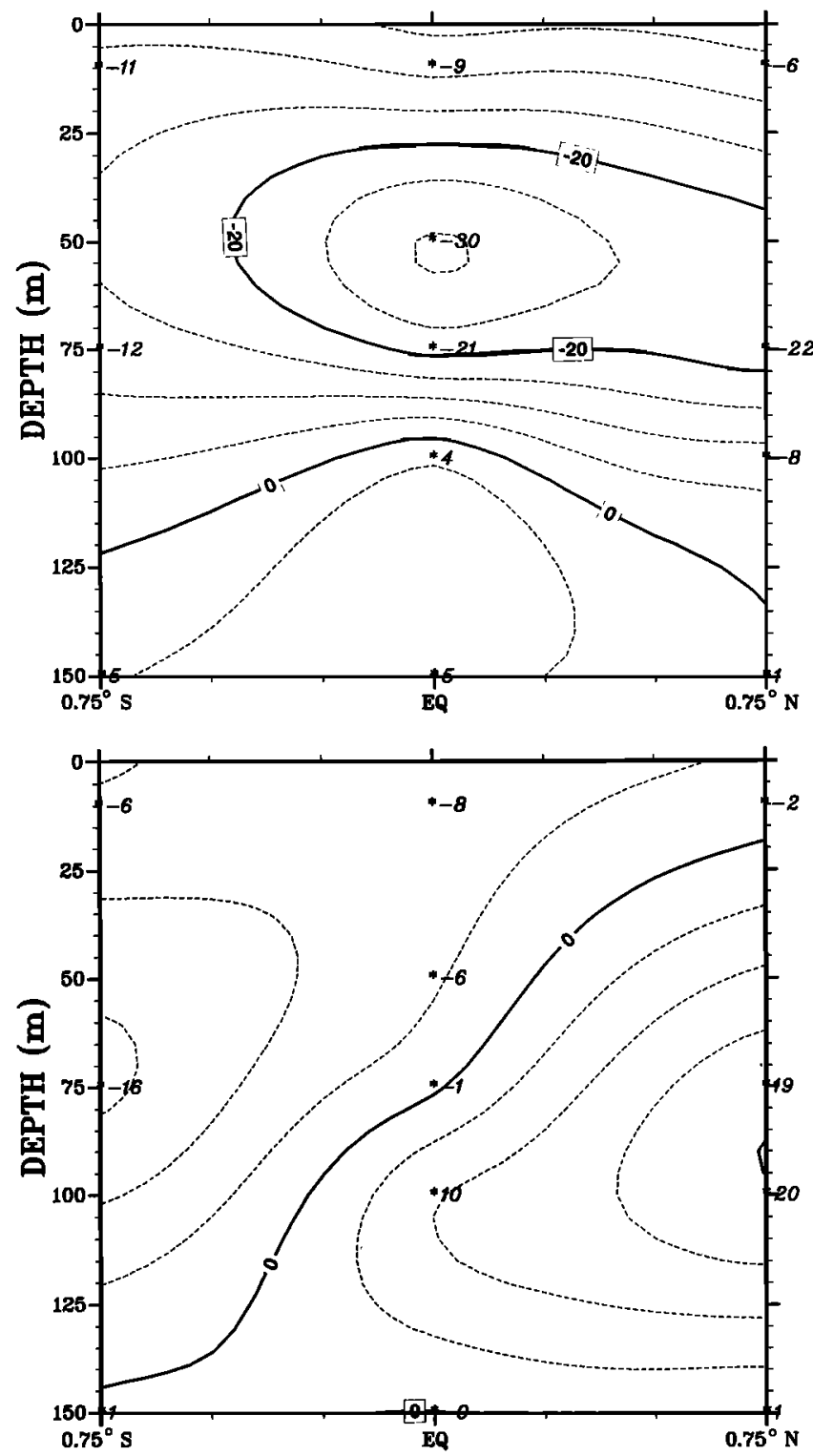

Fig. 5. Isotachs for the EOF (top) mode 1 and (bottom) mode 2 eigenfunctions of data set $\mathrm{A}$, drawn in the meridional plane at $28^{\circ} \mathrm{W}$ between $0.75^{\circ} \mathrm{S}$ and $0.75^{\circ} \mathrm{N}$ over the upper $150 \mathrm{~m}$.

ment from an initial off-equator position $y_{i}$, where $u_{i}=0$, then $u_{0}=\beta\left(y_{i}\right)^{2} / 2$. By defining $L_{I}$ as the standard deviation of a Gaussian distribution for comparisons with the linear least squares fits and with the equatorial Rossby radius of deformation, we obtain $L_{l}=y_{i} / 3$, since a Gaussian distribution reaches nominally small values beyond three standard deviations. It is within this definition that the results for the Gaussian mean distribution agree with the inertial length scale $(101 \mathrm{~km}$ from the Gaussian mean distribution versus 91 $\mathrm{km}$ from $L_{I}$ defined above). The equatorial Rossby radius of deformation, defined as $L_{R}=(\beta / C)^{1 / 2}$ [Matsuno, 1966], where $C$ is the baroclinic Kelvin wave speed, appears as the standard deviation of a Gaussian distribution in the Hermite functions that describe equatorially trapped waves, and it is within this definition that the Gaussian fit to the fluctuations agrees with the equatorial Rossby radius of deformation (a range of $190-360 \mathrm{~km}$ versus $264 \mathrm{~km}$ ).

The confinement of the volume transport fluctuations to the upper $100 \mathrm{~m}$ is also consistent with equatorial long-wave theory. During the SEQUAL experiment the zonal pressure gradient variations decreased rapidly through the thermocline [Weisberg and Weingartner, 1986], and the evolution of these variations was shown to be controlled by equatorial long waves tending to adjust the zonal pressure gradient to the seasonally varying surface wind stress [Weisberg and Tang, 1987]. For the equatorial Pacific Ocean, Halpern [1987], analyzing five years of surface moored current meter data from $0^{\circ}, 110^{\circ} \mathrm{W}$, also shows that the annual variations in zonal flow are largely confined above $100 \mathrm{~m}$.

In summary, zonal volume transport time series were estimated over the upper $150 \mathrm{~m}$ of the water column at $28^{\circ} \mathrm{W}$, using moored current meter data from the SEQUAL experiment obtained at $0.75^{\circ} \mathrm{S}, 0.0^{\circ}$, and $0.75^{\circ} \mathrm{N}$. Gaussian distributions were fit to both the mean transports per unit width and the fluctuations about these means, which were adequately represented by a single EOF mode. In the mean the volume transport was found to be distributed symmetrically about the equator and about $75 \mathrm{~m}$ depth, with a meridional scale width of $101 \mathrm{~km}$ and a magnitude of $20.3 \mathrm{~Sv}$. The fluctuations in volume transport had a standard deviation of 4.7 Sv, and in contrast to the mean the fluctuations were largely confined to above $100 \mathrm{~m}$ depth, with a much larger meridional scale width. The scale width estimated for the mean is consistent with an inertial scale determined by conservation of potential vorticity, and the scale width estimated for the fluctuations is consistent with an equatorial Rossby radius of deformation. The time evolution of the transport fluctuations over the seasonal cycle is in qualitative agreement with that predicted by forced equatorial
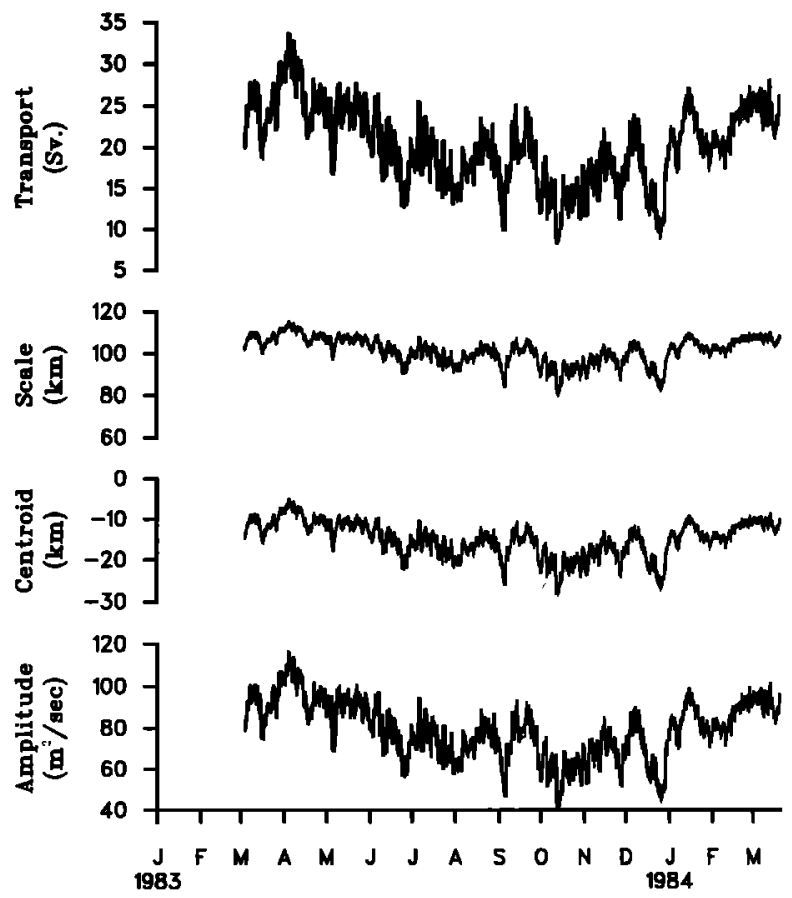

Fig. 6. Time series of the zonal volume transport over the upper $150 \mathrm{~m}$ at $28^{\circ} \mathrm{W}$, estimated by fitting a linear least squares Gaussian distribution to zonal volume transport per unit width at $0.75^{\circ} \mathrm{S}, 0^{\circ}$, and $0.75^{\circ} \mathrm{N}$ using the first EOF mode spatial eigenfunction of data set $A$ and the time evolution function of data set $B$. Included are the parameters of the Gaussian fit: the standard deviation, the centroid, and the amplitude. 
long-wave theory, as well as being in qualitative agreement with previous time series constructions from both shipboard profile data and numerical model results. These findings lead us to hypothesize that different physical processes are controlling the volume transport, integrated across the EUC from the surface, over different time scales. On the time scale of the record length average, inertial dynamics appear to be controlling, while on the time scales of the seasonal fluctuations, linear equatorial long-wave dynamics appear to be controlling. Longer record lengths within a similar dynamical regime will be required to test this hypothesis statistically.

Acknowledgments. Support was provided by the Oceanography section of the National Science Foundation under grant OCE8841927. Additional support for T. Y. Tang was provided by the National Science Council, Taiwan, under grant NSC79-0209-M002a16. The authors thank J. Donovan for his assistance with the data processing.

\section{REFERENCES}

Bubnov, V. A., and V. D. Egorikhin, Study of water circulation in the tropical Atlantic, Deep Sea Res., 26, GATE suppl., 125-136, 1979.

Cane, $M$., The response of an equatorial ocean to simple wind stress patterns, II, Numerical results, J. Mar. Res., 37, 253-299, 1979.

Cane, M., On the dynamics of equatorial currents, with application to the Indian Ocean, Deep Sea Res., 27, 525-544, 1980.

Colin, C., and S. L. Garzoli, In situ wind measurements and the ocean response in the equatorial Atlantic during the Programme Français Océan et Climat dans l'Atlantique Equatorial and Seasonal Response of the Atlantic Ocean experiment, $J$. Geophys. Res., 92, 3741-3750, 1987.

Duing, W., and Z. Hallock, Equatorial waves in the upper central Atlantic, Deep Sea Res., 26, GATE suppl., 161-178, 1979.

Fofonoff, N. P., and R. B. Montgomery, The Equatorial Undercurrent in the light of the vorticity equation, Tellus, 7, 518-521, 1955.

Garzoli, S. L., and E. J. Katz, Winds at St. Peter and St. Paul rocks during the first SEQUAL year, Geophys. Res. Lett., 11, 715-718, 1984.

Halpern, D., Observations of annual and El Niño thermal and flow variations at $0^{\circ} \mathrm{N}, 110^{\circ} \mathrm{W}$, and $0^{\circ} \mathrm{N}, 95^{\circ} \mathrm{W}$ during $1980-1985, J$. Geophys. Res., 92, 8197-8212, 1987.

Halpern, D., and R. H. Weisberg, Upper ocean thermal and flow fields at $0^{\circ}, 28^{\circ} \mathrm{W}$ (Atlantic) and $0^{\circ}, 140^{\circ} \mathrm{W}$ (Pacific) during 19831985, Deep Sea Res., 36, 407-418, 1989.

Hisard, P., and C. Henin, Zonal pressure gradient, velocity, and transport in the Atlantic Equatorial Undercurrent from FOCAL cruises (July 1982-February 1984), Geophys. Res. Lett., 11, 761-764, 1984.

Hisard, P., and C. Henin, Response of the equatorial Atlantic Ocean to the 1983-1984 wind from the Programme Français Océan et Climat dans l'Atlantique Equatorial cruise data set, J. Geophys. Res., 92, 3759-3768, 1987.
Katz, E. J., Seasonal response of the sea surface to the wind in the equatorial Atlantic, J. Geophys. Res., 92, 1885-1893, 1987.

Katz, E. J., J. G. Bruce, and B. D. Petrie, Salt and mass flux in the Atlantic Equatorial Undercurrent, Deep Sea Res., 26, GATE suppl., 137-160, 1979.

Katz, E. J., R. L. Molinari, D. E. Cartwright, P. Hisard, H. U. Lass, and A. de Mesquita, The seasonal transport of the Equatorial Undercurrent in the western Atlantic (during the Global Weather Experiment), Oceanol. Acta, 4, 445-450, 1981.

Matsuno, T., Quasi-geostrophic motions in the equatorial area, $J$. Meteorol. Soc. Jpn., 44, 25-43, 1966.

Moore, D. W., and S. G. H. Philander, Modeling of the tropical ocean circulation, in The Sea, vol. 6, edited by E. Goldberg et al., pp. 319-361, Wiley-Interscience, New York, 1977.

North, G. R., T. L. Bell, and R. F. Cahalan, Sampling errors in the estimation of empirical orthogonal functions, Mon. Weather Rev., $110,699-706,1982$.

Overland, J. E., and R. W. Preisendorfer, A significance test for the principal components applied to a cyclone climatology, Mon. Weather Rev., 110, 1-4, 1982.

Philander, S. G. H., Equatorial Undercurrent: Measurements and theories, Rev. Geophys., 11, 513-570, 1973.

Philander, S. G. H., and R. C. Pacanowski, A model of the seasonal cycle in the tropical Atlantic Ocean, J. Geophys. Res., 91, $14,192-14,206,1986$.

Sverdrup, H. U., Wind driven currents in a baroclinic ocean with application to the equatorial currents in the eastern Pacific, Proc. Natl. Acad. Sci. U. S. A., 33, 318-326, 1947.

Wallace, J. M., and R. E. Dickinson, Empirical orthogonal representation of time series in the frequency domain, I, Theoretical considerations, J. Appl. Meteorol., 11, 887-900, 1972.

Weisberg, R. H., and T. Y. Tang, Further studies on the response of the equatorial thermocline in the Atlantic Ocean to the seasonally varying trade winds, J. Geophys. Res., 92, 3709-3727, 1987.

Weisberg, R. H., and T. Y. Tang, A linear analysis of equatorial Atlantic Ocean thermocline variability, J. Phys. Oceanogr., 20, 1813-1825, 1990.

Weisberg, R. H., and T. J. Weingartner, On the baroclinic adjustment of the zonal pressure gradient in the equatorial Atlantic Ocean, J. Geophys. Res., 91, 11,717-11,725, 1986.

Weisberg, R. H., and T. J. Weingartner, Instability waves in the equatorial Atlantic Ocean, J. Phys. Oceanogr., 18, 1641-1657, 1988.

Weisberg, R. H., J. H. Hickman, T. Y. Tang, and T. J. Weingartner, Velocity and temperature observations during the Seasonal Response of the Equatorial Atlantic experiment at $0^{\circ} \mathrm{N}, 28^{\circ} \mathrm{W}, J$. Geophys. Res., 92, 5061-5075, 1987.

T. Y. Tang, Institute of Oceanography, National Taiwan University, Taipei, Taiwan, 10764.

R. H. Weisberg, Department of Marine Science, University of South Florida, 140 Seventh Avenue, South, St. Petersburg, FL 33701 .
(Received October 29, 1990; revised September 29, 1992; accepted October 15, 1992.) 